\title{
BIRD DIVERSITY ON THE CAMPUS OF THE INDIAN INSTITUTE OF SCIENCE - AN EVALUATION OF TWO METHODS OF ESTIMATION
}

Surendra Varma*

\begin{abstract}
Two methods namely, short strip transect count (SSTC) and point count (PC), were evaluated to select a robust method of estimating bird diversity on the campus of the Indian Institute of Science, a manmade ecosystem. For bird species/h $(P C=6.7$, SSTC $=3.0)$ and the number of birds $/ \mathrm{km}^{2} \mathrm{~h}$ (PC $=184.7, \mathrm{SSTC}=40.3$ ), the PC method encountered more species and individuals in relatively shorter time. The mean number of sightings and species per minute (sightings: PC $=1.31$, SE 0.08, SSTC $=0.94, \mathrm{SE}=0.07$, species: $P C=1.09$, SE 0.06 and SSTC $=0.67$, SE 0.03) were also more in the PC method and the differences are very significant (sightings: $z=3.09, p<$ 0.001 and for species, $z=5.48, p<001)$. Species accumulation curve richness, diversity $\left(H^{\prime}=1.98(P C)\right.$ and 1.75 (SSTC), and evenness (E) (0.610 for PC, and 0.50 for SSTC) also favoured the PC method. These results indicate that the $P C$ is an appropriate method for estimating bird diversity. The paper also discusses the possible ecological reasons for $P C$ being a robust method.
\end{abstract}

Keywords: Bird diversity, species richness, bird count

Asian Elephant Reasearch and Conservation Centre, Centre for Ecological Sciences, Indian Institute of Science (IISc), Bangalore 560 012, India, email: varma@cesiisernefin 


\section{Introduction}

Measures of diversity are frequently used as indicators of the well-being of ecological systems. Birds, being most diverse communities and representing a variety of habitat niches, are potentially useful as indicators of habitat changes and for other conservation-oriented approaches. Understanding such dynamic patterns of diversity is dependent on the methods employed. If there are several methods to choose from, it can sometimes be difficult to decide on the most suitable method of measuring diversity. Here, two methods of measuring bird diversity are compared, and the difference and influence of these methods on studying bird diversity evaluated in a thickly wooded, ornithologically well-known Indian Institute of Science campus. This kind of study may also help in devising strategies for preserving flora and fauna found in man-made ecosystems, which are equally important as other ecosystems, for conserving biological diversity.

\section{Material and methods}

\subsection{Study area}

The study area, the Indian Institute of Science (IISc) campus, has an area of 180 hectares and was probably an open scrubland prior to its establishment in the 1910 s. The land-use pattern has undergone significant changes over the past several years. A major change has been the increase in tree cover and decrease in area under scrub and open land. The campus has a number of species of avenue trees, several species of Cassia, Tabebuia and groves of Ficus Fruityielding trees such as Syzgium, Artocarpus, Anona and Muntungia calabura are found here. Plantations of Acacia, thorny Acacia and Casurina, dense thickets of Lantana, grasslands and open grounds also exist. A small area of grassy marsh and pool is the wetland habitat here These microhabitats provide ideal habitats for a variety of species. More than 100 species of birds have been recorded on the campus (Pers. Obs.).

\subsection{Study method}

The observations of bird diversity studies were made by two methods: (i) Observers walked for 5 min continuously and recorded the bird species encountered while walking and (ii) Observers stopped for $2 \mathrm{~min}$ and recorded the bird species. The methods used will henceforth be referred to as short-strip transect counts (SSTC) for continuous walk method and point counts (PC) for stop method. In the SSTC method, for every five min, an average distance of $30 \mathrm{~m}$ was covered. All birds seen within $20 \mathrm{~m}$ ( $10 \mathrm{~m}$ on either side of the transect) belt were recorded. Totally, 
126 five-min observations were made in the SSTC method. In the PC method, all birds seen within a $10 \mathrm{~m}$ radius of the stationary observer were recorded and 116 were stops made. Information such as the name of the species, the number of individuals, etc was recorded during data collection in both the methods.

The good network of roads and man-made paths in $\mathrm{HSC}$ was used for this study. All samplings were done between 0630 and 0830 , and 1600 and 1800 hours. The data were collected during October-November 1996. There were totally eight observers, divided into four groups of two individuals each. The study area was divided into four different blocks. Every day, two blocks were selected for data collection.

\subsection{Data analysis}

The data were analyzed separately for both the methods. All the 126 five-min observations of the SSTC method were pooled together and species encountered per hour were calculated. In the SSTC method, the area covered was calculated by the width of the strip and the distance covered. Using this, the number of species per hour per $\mathrm{km}^{2}$ was obtained. In the $P C$ method, a $10 \mathrm{~m}$ radius of 116 observations was converted into $\mathrm{km}^{2}$ and the number of species per hour per $\mathrm{km}^{2}$ was obtained. Apart from this, all the 5 and 2 min observations of the SSTC and PC methods, respectively, were standardized into 1 -min observations. Mean sightings and species per $1 \mathrm{~min}$ and their standard deviation (SD) were calculated. Differences were tested using the z-test. To identify the method, which gives maximum species in relatively least ime, we used species and sightings per hour, per $\mathrm{km}^{2}$ and per minute.

As the sample sizes of these two methods were not equal, rarefaction model for measuring species richness was used. The rarefaction method calculates the number of species expected from different communities, if all sample sizes are reduced to a standard size Program RAREFRAC BAS to compute the rarefaction curves and a sample size of $n=500$ were used as standard. At this sample size, the SSTC and PC methods were rated in terms of their species richness. The species richness was compared based on time scale for which species accumulation curve was developed. The cumulative number of species seen after every $15 \mathrm{~min}$ was plotted and the relationship between time and species encountered was identified for these two methods.

Species diversity for these two methods was calculated using Shannon index. It was calculated from the equation.

$$
H^{\prime}=-p_{i} \ln p_{i}
$$

Where $H^{\prime}$ is diversity measure and the quantity $p_{i}$ is the proportion of individuals found in the ith species 
The t test was used to test if the values of diversity indices by the two methods are statistically significantly different. The variance in diversity of the two methods was calculated using the formula

$$
\operatorname{Var} H^{\prime}=\frac{\sum p_{i}\left(\ln p_{i}\right)^{2}-\left(\sum p_{i}\left(\ln p_{i}\right)^{2}\right.}{N}-\frac{S-1}{2 N^{2}}
$$

where var $H^{\prime}$ is its variance

The formula used for the t test is

$$
\dagger=\frac{H_{1}^{\prime}-H_{2}^{\prime}}{\left(\operatorname{Var} H_{1}^{\prime}+\operatorname{Var} H_{2}^{\prime}\right)^{1 / 2}}
$$

where $H^{\prime}$, is the diversity of method 1 and var $H_{1}^{\prime}$ is its variance

The degree of freedom was calculated using the formula

$$
d f=\frac{\left(\operatorname{Var} H_{1}^{\prime}+\operatorname{Var} H_{2}^{\prime}\right)^{2}}{\left.\left[\operatorname{Var} H_{1}^{\prime}\right)^{2} / N_{1}\right]+\left[\left(\operatorname{Var} H_{2}^{\prime}\right)^{2} / N_{2}\right]}
$$

where $N$ is the number of individuals

To identify how equally abundant the species measured by the SSTC and PC methods are, evenness was calculated using the formula

$$
E=H^{\prime} / \ln S
$$

where $H^{\prime}$ is the diversity and $S$ the number of species

\section{Results}

A total of 35 species (Appendix I) were observed during the study period. Table I summarizes the results of the total time spent, the area covered, the number of species, the number of sightings and the total number of birds seen for species for both SSTC and PC methods individually.

Though the time spent for the PC method was relatively lesser than that of the SSTC method ( $4 \mathrm{~h}$ compared to SSTC's $10 \mathrm{~h}$ ), the number of species encountered 
in the PC method was more than that of SSTC 16.7 species/h for PC and 3.0 species/ $h$ for SSTC). The number of individuals encountered per hour per $\mathrm{km}^{2}$ was also more in the PC method (184.7 birds $/ \mathrm{km}^{2}$ per hour for the PC method and 40.3 birds $/ \mathrm{km}^{2}$ per hour for the SSTC method).

Table I. Number of sightings and individuals for both PC and SSTC methods

\begin{tabular}{|c|c|c|c|c|c|}
\hline \multirow{2}{*}{$\begin{array}{l}\text { SI } \\
\text { no }\end{array}$} & \multirow[t]{2}{*}{ Species } & \multicolumn{2}{|r|}{ PC } & \multicolumn{2}{|r|}{ SSTC } \\
\hline & & Sightings & Total number & Sightings & Total number \\
\hline 1 & AWW & 1 & 1 & 3 & 4 \\
\hline 2 & $B D$ & 11 & 12 & 40 & 64 \\
\hline 3 & BK & 0 & 0 & 1 & 1 \\
\hline 4 & $\mathrm{BL}$ & 0 & 0 & 2 & 2 \\
\hline 5 & BRP & 7 & 16 & 19 & 53 \\
\hline 6 & BWK & 1 & 1 & 3 & 3 \\
\hline 7 & $\mathrm{CE}$ & 3 & 5 & 5 & 8 \\
\hline 8 & $C M$ & 30 & 273 & 76 & 981 \\
\hline 9 & GO & 0 & 0 & 2 & 3 \\
\hline 10 & $\mathrm{GI}$ & 2 & 6 & 4 & 15 \\
\hline 11 & $\mathrm{HC}$ & 113 & 335 & 234 & 741 \\
\hline 12 & $\mathrm{HO}$ & 1 & 1 & 0 & 0 \\
\hline 13 & HOS & 0 & 0 & 1 & 1 \\
\hline 14 & $H S$ & 2 & 2 & 2 & 4 \\
\hline 15 & $\mathbb{R}$ & 0 & 0 & 1 & 1 \\
\hline 16 & KO & 20 & 23 & 22 & 24 \\
\hline 17 & MPR & 3 & 5 & 5 & 5 \\
\hline 18 & PFC & 1 & 1 & 1 & 2 \\
\hline 19 & $\mathrm{PH}$ & 4 & 13 & 15 & 37 \\
\hline 20 & PK & 16 & 20 & 25 & 38 \\
\hline 21 & PRS & 6 & 21 & 11 & 17 \\
\hline 22 & RRP & 17 & 52 & 49 & 154 \\
\hline 23 & RVB & 1 & 2 & 0 & 0 \\
\hline 24 & RWL & 0 & 0 & 1 & 1 \\
\hline 25 & SD & 11 & 17 & 17 & 22 \\
\hline 26 & SGB & 5 & 13 & 13 & 18 \\
\hline 27 & $\mathrm{SH}$ & 0 & 0 & 1 & 1 \\
\hline 28 & SMM & 1 & 1 & 0 & 0 \\
\hline 29 & $S M$ & 0 & 0. & 1 & 1 \\
\hline 30 & so & 0 & 0 & $i$ & 1 \\
\hline 31 & $\mathrm{~TB}$ & 2 & 4 & 3 & 3 \\
\hline 32 & IFP & $3 \overrightarrow{1}$ & 61 & 64 & 85 \\
\hline 33 & WBK & 4 & 5 & 6 & 6 \\
\hline 34 & WE & 2 & 2 & 3 & 3 \\
\hline 35 & WHB & 14 & 30 & 20 & 45 \\
\hline
\end{tabular}




\begin{tabular}{lllllll} 
Method Time & $\begin{array}{l}\text { No. of } \\
\text { spent }(\mathrm{h})\end{array}$ & $\begin{array}{l}\text { No. of } \\
\text { species }\end{array}$ & $\begin{array}{l}\text { Species/ividuals } \\
(\mathrm{h})\end{array}$ & $\begin{array}{l}\text { Area } \\
\text { covered } \\
\left(\mathrm{km}^{2}\right)\end{array}$ & $\begin{array}{l}\mathrm{B} \mathrm{i} \mathrm{d} \mathrm{s} / \\
\left(\mathrm{k} \mathrm{m}^{2} / \mathrm{h}\right)\end{array}$ \\
\hline SSTC & 10.5 & 32 & 2334 & 3.05 & 0.075 & 40.3 \\
PC & 3.8 & 26 & 922 & 6.72 & 0.036 & 184.5 \\
\hline
\end{tabular}

Standardizing the observations to mean birds per minute and comparing the results of the SSTC and PC methods it was found that the number of bird sightings and species encountered per minute was more in the PC method. The mean number of sightings per minute for the PC method was 1.31 ( $n=116$ SE 0.08) and 0.94 for the SSTC method, $(n=126 \mathrm{SE} 0.07)$. The mean number of species per minute for the PC method was 1.09 ( $n=116$ SE 0.06) and 0.67 for the SSTC method ( $n=126$ SE 0.03). The $z$ test shows that the differences are very significant (for sightings $z=3.09, p<001$ and for species, $z=5.48, p<$ 001 ), indicating that the PC method encountered more sightings and species of birds in a shorter period of time.

It is expected that as the time spent increases, species accumulation increases at decreasing rate and an average number of sightings and species over a large time span and area may tend to give smaller average. The smaller average for the SSTC method could be due to the same reason. For an acceptable comparison, time spend and area covered for both the methods were equalized. To equalize the time spend for SSTC, $230 \mathrm{~min}$ was taken and found, the mean sightings and species of birds for the SSTC method were $0.60(n=46$ SE 0.06) and $0.50(n=46 \mathrm{SE} 0.043)$, respectively. Apart from this, the actual averages (not standardized to $1 \mathrm{~min}$ observations) of both sightings and species of both the methods were compared SSTC estimated higher averages for both. However, statistically the results were not different $(z=1.134, p>0.05$ for species and $z=0.953, p>0.05$ for sightings). The area covered per hour was equalized to the PC method $\left(0.036 \mathrm{~km}^{2}\right)$ and the data of 62 observations of the SSTC method (area of $0.039 \mathrm{~km}^{2}$ ) were compared with the PC method and the SSTC method estimated $131.1 \mathrm{birds} / \mathrm{km}^{2} / \mathrm{h}$. Based on these results, it can be observed that the PC method encountered more bird sightings and species and number of birds/ $\mathrm{km}^{2} / \mathrm{h}$. 
Our results on species richness based on rarefaction model also favoured the PC method. Using standard sample size of 500 , the expected number of species for the PC method $E\left(S_{500}\right)$ was 26 and for $S S T C, E\left(S_{500}\right) 25$. The number, 26 species, could be expected only at the sample size of 600 for the SSTC method. From these results, it could be concluded that the PC method has shown the highest richness and SSTC the lowest. However, it may be noted that the difference may not be statistically significant and the species increase for the PC method was only one at a standard sample size of 500 (Fig. 1).

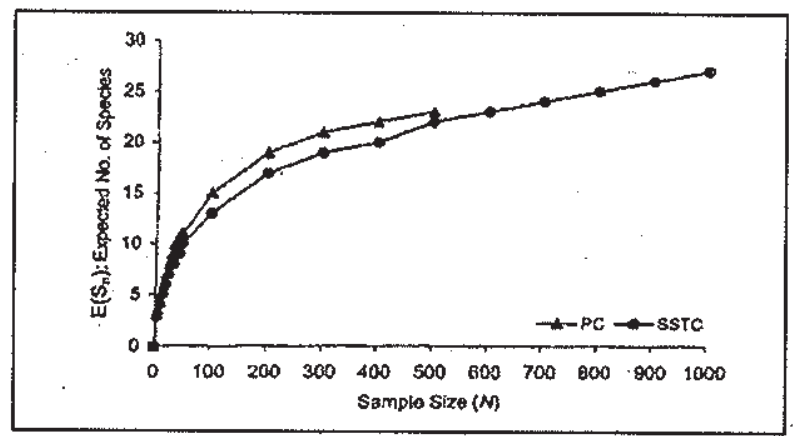

Fig. 1. Rarefaction curves of PC and SSTC methods showing the expected number of species as a function of sample size.

Comparing the results of species accumulation curve of both the methods, we find that the total number of species encountered in the PC method was 26 , achieved in $224 \mathrm{~min}$ of observation, compared to 32 in a period of $570 \mathrm{~min}$ in SSTC method. The 26 species encountered in the PC method were observed in the SSTC method only after $330 \mathrm{~min}$. of observation, needing an additional 100 min of observation in the SSTC method (Fig. 2).

The PC method also led to a higher value of species diversity. The diversity for the $\mathrm{PC}$ method was $H^{\prime}=1.98$, while it was 1.75 for the SSTC method. The t test revealed that the differences are highly significant (df 1745 , t value 4.58, $p<.001$ ) in terms of diversity of birds occurring in them. Hence, the PC method has shown more diversity than the SSTC method.

The measure of evenness for both the methods showed a higher evenness for the PC method ( 0.610 compared to 0.504 of the SSTC method) making the PC method the most appropriate one for measuring species diversity. 


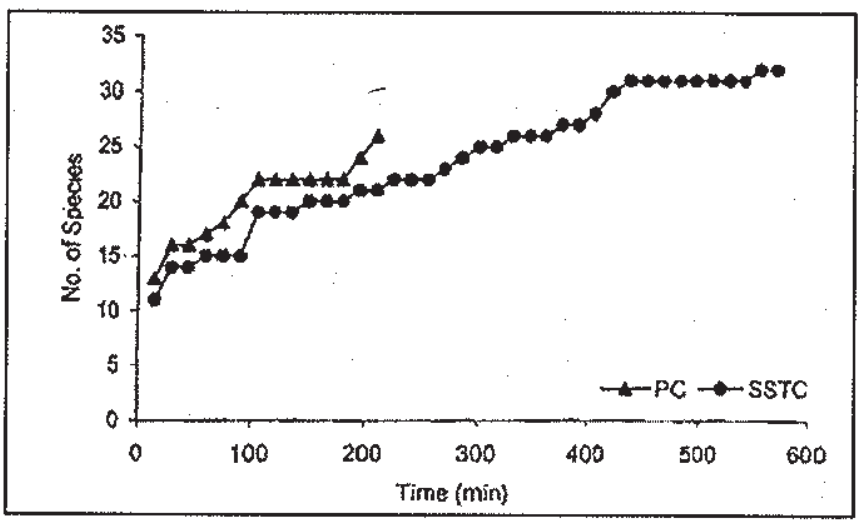

Fig. 2. Species accumulation curves for both PC and SSTC methods as a function of time.

\section{Discussion}

By using diversity indices (Shannon index) for species diversity, it is found that the PC method gives higher diversity measure suggesting that it is an appropriate method for measuring species diversity. Although our results based on the rarefaction model for species richness show that the $P C$ method has the highest richness, the difference may not be significant as the results are not validated by any statistical test. The species increase for the PC method was only one at the standardized sample size of 500 . In the case of species evenness, it is rated between 0 and 1 , value 1 representing equal abundance. In this study, the PC method estimates a higher evenness of 0.6, which is more than that of SSTC (0.5). However, the difference of species is not significantly different.

For all the three exercises, species and sightings per hour, species and sightings per hour per $\mathrm{km}^{2}$ and species and sightings per minute, the $\mathrm{PC}$ method encountered more sightings and species of birds in a relatively shorter time. The results of species accumulation curve for both the methods also favoured the PC method. Based on this it can be concluded that more birds are sighted during the $\mathrm{PC}$ count and it could be a reason for the PC method to show higher species diversity.

The reasons for the PC method being an appropriate method for measuring species diversity could be that during point counts more birds could be sighted per unit time. A similar study experienced that smaller birds tend to be sighted only when the observer stands at one place and observes carefully and are probably missed while walking. For example, it was found that the number of the 
sightings of white eye (Zosterops palpebrosa) nearly doubles in standing as compared to walking. It was also found that the birds of large body size showed no specific patterns. Some species were seen more while standing, while some were seen more while walking. Although the PC method encountered more bird sightings and species, the SSTC method has encountered more rare species than the PC method; however, the number of sightings of these rare birds (for each species) is only one. If more time is spent (it is expected that spending more time and covering larger area has the advantage of encountering more rare species), it can be assumed that those rare species also may be encountered by the PC method.

\section{Conclusion}

The current study was restricted to a limited period of time, as it did not cover all seasons. The seasonal changes in the diversity and their influence on the results could not be evaluated. However, as there was more manpower (with 112 manhours), the study was designed so as to ensure an adequate sample size for measuring bird diversity. These kinds of studies are important as they provide information on the biological diversity and trend in population numbers of different species found in man-made ecosystems. Most of the well-wooded man-made ecosystems, because of rapid urbanization, are becoming increasingly isolated. This isolation has prevented the emigration of species, particularly birds from the neighboring areas. Santharam felt that the $\| I S c$ campus still appears good to support a variety of species, particularly ones such as Black-rumbed Flame back (Dinopium benghalense), Rufous Treepie (Dendrocitta vagabunda), Common lora (Aegithina tiphia) and White-browed Bulbul (Pycnonotus luteorus). These species existed earlier and have in recent years become locally extinct on the campus. Very interestingly, Gadagkar et all reported the sighting of the Blackrumped Flame back on the campus. Thus, this kind of short, quick and wellplanned studies also help to assess the changes in the species diversity and their number.

\section{Acknowledgments}

Mr. I.R. Shankar Raman, Dr. N.V. Joshi, Ms. Maulishree Agrahari and Ms. Cheryl Nath of the Centre for Ecological Sciences, IISc, and Mr. P.R. Jaikrishnan examined the manuscript and suggested many useful changes. I wish to thank the members of the "Nature interest informal group" for their interest and help in collecting the data. 


\section{References}

1. Magurran A.E, Ecological diversity and ifs measurement, Croom Helm Ltd, 11 New Fetter Lane, London, 1988.

2. Shyamal $L$, The birds of Indian Institute of Science Campus-Changes in the Avifauna News! Bird Watchers, 1994, 34(1) 7-9.

3. Suresh H.S. and Bhai H.R, Flora of Indian Institute of Science Campus, Bangalore, Technical report, Centre for Ecological Sciences, Indian Institute of Science, Bangalore, India, 1998, TR No. 77.

4. Ludwig L.A, and Reynolds J.F, Statistical ecology A printer on method's and computing, WileyInterscience, 1988.

5. Varma.S, A study of bird diversity in the Indian Institute of Science Campus, Bangalore India. A comparsion of two different methods (undated, unpublished manuscript).

6. Santharam V, Some random notes and observation on the birds of Bangalore, Newst Bird Wotchers, 1990, 30(1), 5-7.

7. GadagkarV Vet.ol, A blue-throated flycatcher, Indian Great Reed Warbler, Common Rosewich and Lesser Golden backed wood pecker-Four new species in thelndian Institute of Science Campus, Bangalore News/ Bird Watchers 1995 35(4), 69-70.

\section{Appendix I}

Birds sighted during the study period

\begin{tabular}{|c|c|c|c|}
\hline $\begin{array}{l}\text { SI. } \\
\text { no. }\end{array}$ & $\begin{array}{l}\text { Species } \\
\text { code }\end{array}$ & Name & Scientific name \\
\hline 1 & AWW & Ashy Prinia & Prinia socialis \\
\hline 2 & $\mathrm{BD}$ & Black Drongo & Dicrurus macrocurcus \\
\hline 3 & BK & Brahminy Kite & Haliasur Indus \\
\hline 4 & $\mathrm{BL}$ & Rufous-winged Bushlark & Mirafra assamica \\
\hline 5 & BRP & Rock Pigeon & Columba Livia \\
\hline 6 & BWK & Black-shouldered Kite & Elanus caeruleus \\
\hline 7 & CE & Cattle Egret & Bubulcus ibis \\
\hline 8 & $\mathrm{CM}$ & Common Myna & Acirdotheres tristis \\
\hline 9 & GO & Eurasian Golden Oriole & Oriolus oriolus \\
\hline 10 & $\mathrm{Gl}$ & Great Tit & Parus major \\
\hline 11 & $\mathrm{HC}$ & House Crow & Corvus splendens \\
\hline 12 & $\mathrm{HO}$ & Common Hoopoe & Upupa epops \\
\hline 13 & HOS & House Sparrow & Passer domesticus \\
\hline 14 & HS & House Swift & Apus affinis \\
\hline
\end{tabular}




\begin{tabular}{llll}
15 & IR & Indian Robin & Saxicoloides fulicata \\
16 & KO & Asian Koel & Eudynamys scolopacea \\
17 & MPR & Oriental Magpie-robin & Copsychus saularis \\
18 & PFC & Asian Paradise Flycatcher & Terpsiphone paradisi \\
19 & PH & Chinese Pond Heron & Ardeola bacchus \\
20 & PK & Black Kite & Milbus migrans govinda \\
21 & PRS & Purple-rumped Sunbird & Nectarina zeylonica \\
22 & RRP & Rose-ringed Parakeet & Psittacula cafer \\
23 & RVB & Red-vented Bulbul & Vanellus Kranneri \\
24 & RWL & Red-wattled Lapwing & Vanellus cafer \\
25 & SD & Spotted Dove & Streptopella chinensis \\
26 & SGB & White-cheeked Barbet & Megalaima virdis \\
27 & SH & Shikra & Accipiter badius \\
28 & SMM & Small Minivet & Pericrocotus cinnamomeus \\
29 & SM & Scaly-breasted Munia & Lonchura punchtulata \\
30 & SO & Spotted Owlet & Athene brama \\
31 & IB & Common lailorbird & Orthotomus sutorius \\
32 & IFP & Pale-billed Flowerpecker & Dicaeum erythrohynchos \\
33 & WBK & White-throated Kingfisher & Halcyon smyrnensis \\
34 & WE & Oriental White-eye & Zosterops palpebrosa \\
35 & WHB & Yellow-billed Babbler & Turdoides affinis \\
\hline
\end{tabular}

